\title{
Reproductive Health Issues Affecting Displaced Populations
}

\author{
Samantha Guy
}

\begin{abstract}
The provision of reproductive health services for displaced populations has gained momentum since the 1994 International Conference on Population and Development (ICPD). The ICPD Programme of Action sets reproductive health within a rights framework and highlights the needs of refugees and internally displaced populations. This paper looks at the background to reproductive health for refugees, offers some lessons learned from Marie Stopes International's refugee programming experience and highlights possible future interventions.
\end{abstract}

\section{Résumé}

La prise en compte des questions d'obstétrique pour les personnes déplacées a gagnéun surcroîtd'attention depuis la Conférence Internationale sur la population et le Développement de 1994. Le programme d'action ayant découlé de cette conférence place l'obstétrique dans le cadreadéquatet met en relief les besoins des réfugiés et des personnes déplacées à l'intérieur des frontières nationales. Cet article propose un rappel historique de la question de l'obstétrique pour les réfugiés, suggère quelques leçons à tirer de l'expérience d'organisation des réfugiés de Marie Stopes International, et signale les interventions futures possibles.

\section{The Context - Agency Initiatives}

International recognition of the pressing demand for reproductive health services in refugee settings is well docu-

Samantha Guy runs Marie Stopes International's Reproductive Health for Refugees Initiative. Marie Stopes International is at the forefront of international initiatives to institutionalise reproductive health in refugee settings. mented. ${ }^{1}$ Although international conventions and agreements have been ratified, reproductive health services for refugees are still being neglected or delayed.

The principles of reproductive health arise under specific international human rights instruments, ${ }^{2}$ applicable to all persons, including refugees, without discrimination.

"The human rights of women include their rights to have control over and decide freely and responsibly on matters related to their sexuality, including sexual and reproductive health, free of coercion, discrimination and violence."

Fourth World Conference on Women, Platform for Action, Beijing, 1995

It was in Cairo, at the 1994 International Conference on Population and Development, (ICPD) that the reproductive health needs of refugees were officially recognised for the first time at a UN conference:

"In planning and implementing refugee assistance activities, special attention should be given to the specific needs of refugee women and refugee children. Refugees should be provided with access to adequate accommodation, education, health services, including family planning."

Programme of Action, International Conference on Population and Development, Cairo, September 1994, Para 10.25

"Reproductive health is a state of complete physical, mental and social well-being and not merely the absence of disease or infirmity in all matters relating to the reproductive system and to its functions and processes. Reproductive health therefore implies that people are able to have a satisfying and safe sex life and that they have the capability to reproduce and the freedom to decide if, when and how often to do so."

Programme of Action, International Conference on Population and Development, Cairo, September 1994, Para 7.2

A central achievement of ICPD was its promotion of a comprehensive approach to meeting people's reproductive health needs. The rights of women are central to the Programme of Action, which calls for the full and equal participation of women in civil, cultural, economic, political and social life. Until 1994, population programmes emphasised family planning services. The Cairo Programme of Action presents an alternative agenda, based on a humanrights framework, which recommends that reproductive health $(\mathrm{RH})$ should be made available to all. It calls for comprehensive RH services, designed with the involvement of women, to serve women's needs and advance women's rights.

As a result of the ICPD, the InterAgency Symposium on Reproductive Health in Refugee Situations was convened in 1995 . Fifty agencies committed themselves to improving reproductive health provision for refugees and produced the Inter-Agency Field Manual on Reproductive Health in RefugeeSituations. In addition, the Inter-Agency Working Group on Reproductive Health in Refugee Situations (IAWG) was formed, comprising 32 members including NGOs, donor agencies and researchers. The final version of the field manual has just been produced and is available from the United $\mathrm{Na}$ tions High Commissioner for Refugees (UNHCR). ${ }^{3}$ 
Recognising the pressing need to introduce reproductive health care as early as possible, the concept of the Minimal Initial Service Package (MISP) was developed by the IAWG. The MISP is specifically designed to facilitate the timely and appropriate delivery of reproductive health services in the initial acute phase of an emergency situation and to plan for services as the situation develops. The MISP concept includes: human resources; guidelines and training for the implementation of selected interventions; material resources, including essential drugs, and basic equipment.

To provide the material resources of the MISP, UNFPA has developed The Reproductive Health Kit. The kit is divided into 12 subkits for use at different levels of health facility. ${ }^{4}$

\section{Reproductive Health for Refugees Consortium \\ During the ICPD, CARE, International} Rescue Committee (IRC), John Snow International Research \& Training (JSI), Marie Stopes International (MSI) and the Women's Commission for Refugee Women and Children (WCRWC) united to form the Reproductive Health for Refugees (RHR) Consortium. Its membership has recently been extended to include: American Refugee Committee (ARC) and Colombia University Centre for Population and Family Health. The aim of the RHR Consortium is to institutionalise reproductive health for refugee women, men and adolescents worldwide in accordance with the Cairo Programme of Action. The Consortium has developed training modules and needs assessment tools, established an advocacy group of refugee women from around the world and implements a small grants programme. Currently in development is a set of monitoring and evaluation tools for $\mathrm{RH}$ in refugee settings. ${ }^{5}$

\section{The Provision of Reproductive Health Care in Emergency Settings}

Refugee and emergency settings compound many of the problems faced by women. It is imperative to ensure that a lack of comprehensive health services does not add to the suffering of refugee women.

Reproductive health entails much more than the skeleton maternal and child health services provided in many refugee settings. An effective programme of reproductive health care is sensitive to the different needs of men and women, of differentethnic and cultural groups, and of different age groups. It must be accessible and available to single women, widows, older women, adolescents and men.

In Sri Lanka, MSI promotes community participation in the project to help ensure services are appropriate to all sectors of the community and as a result has seen a marked increase in the care seeking behaviour of the internally displaced communities it serves.

Reproductive health for refugeescovers the following technical areas:

- safe motherhood (including antenatal, delivery and post-partum care)

- prevention and management of the consequences of sexual and gender violence

- family planning

- prevention and treatment of sexually transmitted diseases and HIV/ AIDS

-emergency obstetric care, including the treatment of abortion-related complications

While food, water, shelter and primary health care are provided as a matter of course in emergency settings, reproductive health care provision is far from universal. Lessons from refugee settings worldwide clearly reveal that ignoring the reproductive health needs of refugees can threaten the lives of many people (WHO, 1997, UNHCR, 1999, RHR Consortium, 1998), yet this crucial component of emergency aid is often overlooked by agencies. Reproductive health has been referred to by some as an optional second phase in- tervention rather than a first phase imperative. However, as the majority of crises prove, certain reproductive health services are required from the moment displacement occurs such as prevention and management of the consequences of sexual violence, reduction of HIV transmission, prevention of excess neonatal and maternal morbidity and mortality, planning for comprehensive service delivery. Other services can beestablished as the situation develops such as comprehensive family planning, prevention and treatment of STDs, ante- and post-natal care, counselling, management of consequences of unsafe abortion.

Most refugees are from countries where health indicators are already poor. Flight from war, civil or ethnic conflict or natural disaster exacerbates existing health problems. During flight, women, in particular, are vulnerable to sexual violence and abuse. Even once women reach relative safety, conditions still prevail that further contribute to their ill health: malnutrition and epidemics, an absence of law and order, increased responsibility for households in the absence of male family members, and breakdown of pre-existing family structures. Despite a lack of hard data, there is ample evidence (Palmer 1998, UNHCR 1999, UNFPA 1999, RHR Consortium 1998) to support the need for reproductive health services in refugee settings. Women are most affected by reproductive health problems and for refugee women this burden is further compounded by the precariousness of their situation.

Ithas been shown that women in refugee settings experience ( Palmer 1998, RHR Consortium, 1998, Busza and Lush, 1999):

1. Higher maternal mortality and morbidity as a result of:

- poor nutrition

- repeated, frequent pregnancies

- lack of clean, safe delivery care

2. Increased (often unsafe) sexual activity, which results in an increase in HIV/ AIDS and sexually transmitted diseases due to:

- use of sexual favours in exchange for food, money or protection 

ation

- rape as a tool of coercion or humili-

- breakdown of family and social structures, and accompanying behavioural change

-boredom

3. Increased fertility rates due to:

-improvements in child survival rates

- pressure on women to rebuild the population

- lack of birth spacing/family planning information and supplies

InSierra Leone, experience indicated that fertility was high in the camp environment. Boredom was identified as leading to the appearance of unsafe sexual activity in the camp. An informal assessment was carried out to discover the reasons why women wanted to have many children and the results were given as:

- willingness to replace those lost during the war

- children represented the only stability for women in new relationships

-increased food rations

It is important that RH interventions are not only timely but also appropriate. In an emergency, itmay be easy to overlook particular refugee needs in the urgency of providing services. Refugee participation is vital in ensuring that services are tailored to users' needs.

\section{Lessons Learned and Recommendations From MSI's Refugee Projects}

There are a number of issues which differentiate refugee settings from conventional settings and must be taken into account in service delivery and programme implementation.

Agencies operating within a refugee setting need to retain a greater degree of flexibility in order to remain responsive to the often rapidly changing needs of a refugee community. Services required at the onset of an emergency will develop and expand as the situation stabilises. In addition, reproductive health agencies must be prepared to provide primary health care services as well as to encourage primary health providers to integrate reproductive health into their service mix.

The highly political nature of complex emergencies can make the provi- sion of reproductive health care a particularly sensitive issue. Therefore, it is imperative to ensure the full participation of the refugee community, particularly women and adolescents, in all stages of the planning, design and implementation of services.

It is also important to ensure that services reach the host/local population as well as the displaced population, not just to reduce the possibility of tension between the communities but also to make clear that there is noethnic dimension to the provision of services.

Refugees are not always in camp environments, thus services also need to be accessible and available to those living within the host community.

Health committees comprised of key community representatives should ensure the ongoing acceptability and appropriateness of services liaising between the project and targetcommunities.

Community volunteers should be identified and trained to become health providers. This strategy ensures valuable skills are not lost during displacement, new skills can be developed in preparation for the return process, and services remain appropriate to the target population.

Extra care should be paid to ensure that quality of care is not compromised during the provision of comprehensive sexual and reproductive health services. Specialist technical support for specific service components should be considered to ensure continuing high quality services as well as to monitor quality of care issues.

Appropriate information education and communication messages and materials in consultation with community leaders and health committees should be developed. Materials may be available from the country of origin or locally produced material could be adapted to suit the particular situation.

\section{Recommendations for Future Action}

MSI and the RHR Consortium are at the forefront of organisations undertaking a range of activities to guarantee the provision of reproductive health services in refugee settings. The following set of recommendations is drawn from global programming experiences and highlights some of the areas in which action must be taken to ensure reproductive health care provision for refugees.

\section{A Broad Perspective}

Solutions for short-term problems should be matched with long-term needs and should have a positive longterm developmental impact for the whole community.

\section{Advocacy and Fundraising}

A concerted advocacy programme to promote increased attention and action for RHR aimed at policy makers, government officials, UN agencies, donors, aid workers, the media and the general public.

Implementing agencies need to challenge long standing organisational priorities to build institutional capacity and commitment to RHR.

\section{A Participatory Approach}

RHR programmes must be based on participation, capacity building and strengthening representative organisations.

Sensitisation and assistance to local communities should be established in order to alleviate tensions between lo$\mathrm{cal}$ and refugee populations.

Greater understanding of the cultural and traditional values of refugee communities willensure culturally appropriate services and resources are available.

Co-ordination between agencies is imperative in order to avoid duplication and to ensure that the full range of reproductive health services are available.

NGOs must ensure that camp layout really considers women's and children's issues. The consequences of poor camp layout on women's health can lead to high medical and human resource costs.

Greater representation of women in decision-making positions in implementing agencies and refugee organisations, including translators, will help ensure services are appropriate 
and accessible to refugee women and their families.

Programmesmust take the long-term perspective in which women are perceived as crucial in the rehabilitation and reconstruction process.

Involvement and education of refugee men about their responsibilities is critical to women's health status; particular attention should be paid to the needs of adolescents.

\section{Training and Capacity-Building Needs}

Greater training and awareness among field staff on practical protection measures for preventing and responding to sexual violence is needed.

Public health awareness campaigns should beimplemented among refugee and displaced populations, incorporating training in good reproductive health practices.

Increased resources, both financial and human, to implement comprehensive $\mathrm{RH}$ programmes are needed.

Greater access to female protection, medical staff and female interpreters would ensure that refugee women are more able to report incidents of sexual violence.

\section{Research and Development}

Further research and study into the health, behaviour and characteristics of refugees and internally displaced persons is needed to further develop the design and implementation of reproductive health care services.

Development of tools to assist managers and field staff in implementation of comprehensive $\mathrm{RH}$ programmes are needed.

\section{Conclusion}

The challenge facing all organisations is to ensure that advances made at the policy level are translated into increased action and commitment at the field level.

\section{References}

Busza, J. and L. Lush. Planning reproductive health in conflict: a conceptual framework. Soc Sci Med 49 (1999) 155-171.

Palmer, C.A. Reproductive health and displaced populations. London: Overseas Development Institute, 1998. (Relief and Rehabilitation Network Paper 24).

RHRConsortium. Refugees and Reproductive Health Care The Next Step. 1998.

Toubia, N.(1995), "Doing More with Less: The Marie Stopes Clinics in Sierra Leone", Population Council, New York., UNFPA. Reproductive Health Services in Crisis Situations. New York, 1999.

UNHCR. Inter-Agency Field Manual on Reproductive Health in Refugee Situations Geneva,1999.WHO Safe Motherhood Newsletter Issue 23, 1997.

\section{Notes}

1. Cairo Programme of Action 1994, Interagency Symposium on Reproductive Health in Refugee Situations 1995, InterAgency Field Manual on Reproductive Health in Refugee Situations, 1999.

2. Universal Declaration of Human Rights, Convention on the Rights of the Child, Convention on the Elimination of All Forms of Discrimination against Women, International Covenant on Civil and Political Rights.

3. Centre for Documentation for Refugees fax: 41227397367 email: cdr@unhcr.ch.

4. For a copy, contact UNFPA local offices or Emergency Relief Office fax: +4122979 9049 email: unfpaero@undp.org

5. For further information on the RHRConsortium contact: Samantha Guy, MSI, tel: 44 171574 7346, fax: 44171574 7418, email: sam.guy@stopes.org.uk or Rachel Jones, WCRWC, tel: 1212551 3112, fax: 1212 551 3180, email: rachel@intrescom.org.a

\section{The Upcoming}

\section{Issues of Refuge:}

- Religious Refugees

- Challenges in Refugee Service

Delivery

- RefugeerRetum

- A speciallissure on East Timor
Backgroundinformation on the

Centre for Refugee Studies

The Centre for Refugee Studies (CRS) is an organized research unit of York University. Founded in 1988, the Centre for Refugee Studies is successor to the Refugee Documentation Project created in 1981 for the conservation and analysis of research documents and datacollected by Operation Lifeline during the Indochinese Boat People crisis. In 1991, CRS was designated as a Centre of Excellence by the Canadian International Development Agency (CIDA).

The Centre for Refugee Studies fosters interdisciplinary and collaborative research in all of its undertakings. Our efforts are focused in areas related to a comprehensive research programme expanding from theoretical to institutional research on the aforementioned areas of study. In carrying out this research, CRS networks with Canadian and international development agencies and academic institutes. CRS invites scholars from abroad to share in the research. Canadian and international students are supported to undertake field studies and conductrelated research. Joint researchactivitieswithinstitutionsin the developing world are underway. CRS plays a significant role in an advisory capacity with Canadian government and otheragencies. 